\title{
INVESTIGATING THE EFFECT OF TEXTUALIZATION ON LEARNING VOCABULARIES AMONG IRANIAN EFL LEARNERS
}

\author{
Nazal Allahmoradi, MA. , Ilam University, IRAN
}

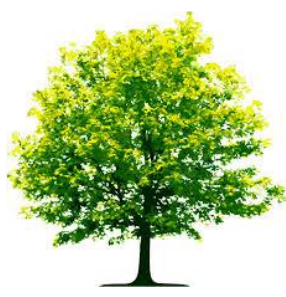

Keywords: $\quad$ Textualization, EFL learners, Vocabulary.

\begin{abstract}
A B S T R A C T
Both first language (L1) learners and second language (L2) learners may incidentally gain knowledge of meaning through reading. While researchers tend to agree that incidental learning is responsible for the vast majority of L1 vocabulary learning, there is some suggestion that explicit learning of vocabulary may be responsible for most L2 vocabulary learning However, researchers agree that incidental vocabulary learning should be encouraged and incorporated into L2 learning. - There is no relationship between textualization and learning vocabulary among Iranian EFL learners. The present research aims at investigating the effect of textualization on learning vocabularies want to investigate the methods of learning vocabularies. Research method in the present study is descriptive-analytic and data were collected by standard tests. The findings of the present research indicated that there is a relationship between textual authority and learning vocabulary among Iranian EFL learners.
\end{abstract}

Citation: Nazal Allahmoradi (2018). Investigating The Effect Of Textualization On Learning Vocabularies Among Iranian Efl Learners. International Journal of Advanced Multidisciplinary Scientific Research (IJAMSR ) ISSN:2581-4281 Vol 1, Issue 6, August, 2018, \#Art.616, pp 51-62

\section{Introduction}

A thorough observation of the conduct of students with learning disabilities (hereinafter: LD) throughout the years shows that they all seem to be able to process information, but they do it inefficiently resulting in a difficulty in activating abstract thinking levels in L2 reading context. Gersten et al. (2001) contend that since reading involves language abstractions it is important to understand the nature of the reading comprehension problems of LD's and adopt reading approaches accordingly. For instance, in a research conducted on Iranian medical students (Jahromi, 2014) who had to cope with extensive reading of texts in English, it was found that applying "bottom up". Strategies such as skimming and scanning, improved the reading comprehension achievements (hereinafter: RCA) of both high and low capable readers. Another problem LD's demonstrate is their disbelief in their academic ability, 


\section{International Journal of Advanced Multidisciplinary Scientific Research (IJAMSR) ISSN:2581-4281}

low self- efficacy, (Bandura, 2006) especially in L2 context, which may be developed due to their negative self-perception as learners. According to Dewck (1999) the development of self- efficacy is affected by different ability conceptions-entity versus incremental. Unlike incremental theorists, entity theorists believe that smartness and intelligence are fixed and therefore rarely make an effort to overcome their problems. Besides that, being diagnosed as "learning disabled" often mistakenly implies a limited intelligently potential. Hence, one of the aims of the intervention program (hereinafter IP) is to weaken these potential feelings while trying to improve students' academic reading competence.

\section{Statement of the Problem}

It is important to note that research shows that time in itself, allotted to reading, doesn't have a significant effect on learners' RCA. In a year-long reading intervention program (Wanzek, 2011) during which middle school students with identified learning disabilities received daily $50-\mathrm{min}$ reading sessions, no significant differences were found between the group that received the intervention program to the one that didn't, regarding passage comprehension. This emphasizes the need to focus on explicit, conscious and concrete strategic reading as much as possible. To overcome these difficulties, the IP tries to increase learners' RCA by imposing Mediated Learning Experiences (Feurstien, 2004). It mediates between the learners and expository texts in a second language (hereinafter L2) to improve not only their RCA but also their academic self- efficacy (hereinafter ASE). It lays a systematic concrete thinking 'track' that forces the learners to demonstrate active, accurate and consistent behavior (Galperin, 2010; Zohar, 2013) which is practiced through metacognitive activities (Flavell, 1992). Specifically, learners are provided with strategies to decode expository texts, trying mainly to grasp their main ideas vs. their supporting details, their purpose and their general mood. This is done by stimulating concrete thinking skills; marking specific items in a text, some of which are known in advance, and following systematic procedures to regulate their thinking. Vocabulary learning is dominant in language acquisition, whether the language is second or a foreign language (Folse, 2004; Mehring, 2005). The importance of vocabulary in determining the success of a reading comprehension has long been established. The knowledge of word meanings and the ability to access the knowledge efficiently are recognized as an essential factor in reading comprehension (Ali \&Mohd. Ayub, 2012; Bee Eng\& Abdullah, 2003). Moghadam, Zainal and Ghaderpour (2012) state that when a reader does not know many words in a text, such condition would hinder the effectiveness and efficiency of text processing, which leads to difficulties in the reader comprehending the text. Since word recognition and lexical access often prevent comprehension, providing vocabulary instruction may help improve students' reading comprehension skills (Curtis \& Longo, 2001). Second language learners are typically conscious in their limitations in their vocabulary knowledge which deficit would hinder their ability in performing reading comprehension tasks successfully (Read, 2004). Past studies on vocabulary in both first language (L1) and second language (L2) have indicated that knowledge on vocabulary is one of the best predictors of reading ability and the capability to obtain new details from texts (Nation, 2001; Qian, 2002; Read, 2000; Tannenbaum, Torgesen\& Wagner, 2006). The present study was carefully designed to gain insight into the effects of context on incidental vocabulary 


\section{International Journal of Advanced Multidisciplinary Scientific Research (IJAMSR) ISSN:2581-4281}

learning. Perhaps due to the length of the texts and the large number of encounters with target words, previous L2 research has provided little information about the contexts in which target words were met. Short contexts, each containing a single target word were used in this study.

So the present research aims at answer to following questions:

- 1-Is there any relationship between textualization and learning vocabulary among Iranian EFL learners?

- 2- Is there any relationship between text authority and learning vocabulary among Iranian EFL learners?

- 3- What are the factors of textualization for learning vocabulary among Iranian EFL learners?

\section{Research Variables}

\subsection{Textualization}

Both first language (L1) learners (Jenkins, Stein, \&Wysocki, 1984; Nagy, Anderson, \& Herman, 1987; Nagy, Herman, \& Anderson, 1985; Shu, Anderson, \& Zhang, 1995) and second language (L2) learners (Day, Omura, \&Hiramatsu, 1991; Dupuy\&Krashen, 1993; Hulstijn, 1992; Pitts, White, \&Krashen, 1989; Waring \&Takaki, 2003) may incidentally gain knowledge of meaning through reading. While researchers tend to agree that incidental learning is responsible for the vast majority of L1 vocabulary learning (Nation, 2001; Schmitt, 2000), there is some suggestion that explicit learning of vocabulary may be responsible for most L2 vocabulary learning (Laufer, 1991, 2001; Laufer\&Paribakht, 1998; Webb, 2008). However, researchers agree that incidental vocabulary learning should be encouraged and incorporated into L2 learning (see, for example, Hunt \&Beglar, 2005; Nation, 2001; Schmitt, 2000; Waring \&Takaki, 2003). Because learners incidentally gain knowledge of words in small increments, building upon their previous gains through repeated encounters until a word is known, incidental vocabulary learning can be a relatively slow process when there are long gaps between encounters. Currently it is not clear how many encounters are needed to learn an unknown L2 word. Hulstijn, Hollander, and Greidanus (1996) found that there was little difference between encountering target words once or three times. Rott (1999) suggested that six encounters may be enough to learn a word. Horst, Cobb, and Meara (1998) suggested eight encounters are needed, Saragi, Nation, and Meister (1978) suggested 10 encounters, Webb (2007a) suggested that more Webb: The effects of context on incidental vocabulary than 10 encounters are needed, and Waring and Takaki (2003) reported that it may take more than 20 encounters to incidentally learn the meaning of a word. Moreover, in some of the studies the number of encounters needed to learn the meaning of a word varied considerably between the target words (Horst, et al., 1998; Saragi et al., 1978). Context may be one reason the number of repetitions needed to learn individual words varies. In some sentences the meaning of an unknown word might be transparent, but in others it may be opaque. Beck, McKeown, and McCaslin (1983) suggested that many contexts may be deceptive, leading learners infer an incorrect meaning. In studies that involve reading books, there may be too many encounters for researchers to take each context into account. However, it could be expected that target words 


\section{International Journal of Advanced Multidisciplinary Scientific Research (IJAMSR) ISSN:2581-4281}

that are met repeatedly in sentences that offer some information about the meaning of a word are going to be learned before those that appear in less informative or misleading sentences. Unless the context is taken into consideration, it may be difficult to make an accurate assessment of incidental vocabulary learning. This may be particularly true in L2 learning where the number and frequency of encounters with unknown words are likely to be less than in L1 learning. The context may have been the reason for the contrasting results in Rott (1999) and Hulstijn et al. (1996). In the Rott (1999) study, the texts were created with enough contextual clues for the learners to be able to infer the meaning of the target words. Whereas, in the study of Hulstijnetal., the text was authentic, and the researchers had determined that it was "extremely difficult to infer the exact meaning" of the target words from the context (p. 330). Differences between the types of contexts used in research may often account for the conflicting results. This may be the case in many studies of incidental learning because a large variety of contexts have been used. For example, Herman, Anderson, Nagy, and Pearson (1987) used four different types of context in a study of incidental vocabulary learning. They used a 1,230-word passage from a text and three edited versions with varying degrees of implicit and explicit clues about the target words. Other contexts used in incidental learning of vocabulary experiments were a novel (Saragi et al., 1978), a graded reader (Horst et al., 1998), specially constructed paragraphs (Jenkins, Stein, \&Wysocki, 1984), and narrative and expository texts of about 1,000 words (Nagy, Herman, \& Anderson, 1985). Studies on learning from context have used single sentences (Dempster, 1987; Laufer\&Shmueli, 1997), multiple sentences (Dempster, 1987), L2 sentences together with their L1 translations (Griffin, 1992), L1 sentences containing the L2 target vocabulary (Pickering, 1982), three sentences one of which was a definite (Gipe\& Arnold, 1979), and L1 and L2 glossed passages (Laufer\&Shmueli, 1997). The wide range of contexts may lead to misinterpretation of results. Would students learning vocabulary from a specially constructed passage containing many clues about a target word's meaning learn as easily from an authentic text? Probably not (Beck et al., 1983; Herman et al. 1987), without a clear definition of context, it seems likely that results will continue to vary between studies.

\subsection{Vocabulary}

Vocabulary is the backbone of any language. Without extensive vocabulary knowledge e, even those who show mastery of grammar might experience the failure to communicate. Many foreign language learners know the feeling of not being able to remember the right word instantly in a conversation because of the limited range of vocabulary they know. This feeling of inadequacy often hinders further development of the language. On the other hand, the vocabulary does help language learners to form sentences and express themselves in meaningful ways. It has been proved to be powerfully related to L2 acquisition with many studies as well. Mastery of vocabulary can only be achieved with the teaching strategies that appeal to various learning styles. Recent studies have proven many benefits of different technology-based instructional materials for effective verbal and written communication (Schmidt \&Hegelheimer, 2004; Pazio, 2010; Khazaei\&Dastjerdi, 2011). Therefore, many higher education institutions today are using blended learning as a supplementary means in developing students' vocabulary knowledge. Blended learning approach in teaching foreign language 


\section{International Journal of Advanced Multidisciplinary Scientific Research (IJAMSR) ISSN:2581-4281}

has become a matter of considerable interest to language teachers all over the world, As opposed to pure elearning which refers to using only electronic media to learn, blended learning supplement traditional face-toface teaching and learning environment with different kinds of technology-based on structure. Bielawaski and Me tcalf (2003) report that blended learning focuses on optimizing the achievement of learning objectives by applying the right learning technologies to match the right learning styles to transfer the right skills to the right person at the right time. Teaching vocabulary through web-based tools is not totally a new trend. What is new is the "expectation" of our learners to use technology in and out of the classroom as part of the learning process. Concerning the individual learner differences and classroom instruction, Lightbown and Spada (2013) also believe that teachers can help learners expand their repertoire of learning strategies and thus develop greater flexibility in their ways of approaching language learning. Thus, various instructional materials, including videos, blogs, online forums and other digital tools provide students opportunities to practice the language outside the class. Most of the researchers who have studied blended learning approach and its place in enhancing vocabulary knowledge listed a great number of positive effects. Zhang, Song and Burston (2011) examined the effectiveness of vocabulary learning via mobile phones and compared two groups of students at a Chinese university. While one group of students analyzed a selected list of vocabulary via text messages, the other group of students worked on the same list through paper material.. When students' test results were compared, their findings revealed that "students can learn vocabulary more effectively short-term via mobile phones than with paper material". Similarly, Khazaei\&Dastjerdi (2011) made a comparative study on the impact of traditional and blended teaching on EFL learners'.Vocabulary acquisition. The work proposed to explore the application of SMS to the blended method of teaching L2 vocabulary. Students were measured on their identification and recall of vocabulary items. The results brought out that the students who experienced the learning content through blended teaching approach had more serious test results than the group of students who received the learning content in the traditional fashion. Established on the inquiry findings, they confirmed "the significant supplementary role of Mobile-Assisted Language Learning (MALL) in the teaching of new vocabulary items. "Yi it et al. (2013) also used blended learning model to optimize learning in teaching Algorithm and Programming course in Computer Engineering Education in SüleymanDemirel University Computer Engineering Department. In their comparative study, blended learning is achieved through a Learning Management System (LMS) of the university. Evaluation was based on students' homework, midterm and final exam grades of the students. The outcomes of the study showed in blended learning education, education was more effective; students' achievements were more well than expected in comparison to traditional training, however; algorithmic thinking abilities of pupils who enrolled in the Algorithm and Programming Course in blended and traditional education were close There are very few empirical studies in the literature which found blended learning instruction had no impact on students' academic accomplishments. Alshwiah (2009) investigated the effects of a proposed blended learning strategy and analyzed students' attitudes toward the English language at Arabian Gulf University. The sample was divided into two groups: control group and experimental group. Findings indicated no significant difference between two 


\section{International Journal of Advanced Multidisciplinary Scientific Research (IJAMSR) ISSN:2581-4281}

groups regarding achievement or attitude towards English Language. Similarly, Chang et al. (2014) conducted a study to examine the effects of blended elearning on electrical machinery performance. Participants were two classes of 11th graders majoring in electrical engineering. The participants were randomly selected and assigned to the experimental group or the control group.

The effectiveness of using L1 words in learning L2 vocabulary items is supported by Kroll and Stewart's (1994) Revised Hierarchical Model (RHM) which aims to explain how L2 vocabulary items are represented and accessed in the mind. According to this model, for less proficient L2 learners, the link between the L2 vocabulary items and the conceptual system is established through the L1 lexicon which has already linked to the conceptual system. In other words, less proficient learners process words in L2 by depending on their lexical knowledge in their L1. However, as proficiency increases, the dependency of the L2 lexicon on L1 lexicon to reach conceptual system decreases and learners use the direct concept-to-L2 lexicon link to process words rather than relying on their L1 lexicon. With this model, the effectiveness of using L1 words to establish the initial form-concept link of the new L2 words has been supported by several researchers and it has been proposed that novel L2 vocabulary items are stored more effectively when they are linked to their L1 equivalents (Barcroft, 2002; Kroll \&Curely, 1988). Another well-known L2 vocabulary instruction method involves the use of pictures. Up to present several studies on memory have pointed out to the importance of pictures in enhancing memory performance (e.g., Nelson, 1979; Paivio, 1991; Paivio\&Csapo, 1973). In general, these studies demonstrate that in tasks which requires the recall of a list of items, items presented in the form of pictures are being called with more ease than those items presented in verbal form. Research on foreign language learning as well indicates that visual aids such as photographs and videos promote comprehension of L2 text materials better than purely verbal descriptions (e.g., Mueller, 1980; Omaggio, 1979).

\subsection{Learning strategies}

These strategies, at the starting point, require learners to activate their sight sense to locate meaningful details and their touch sense to make them to maintain attention; what makes it manageable for all students and triggers higher levels of thinking such as analyzing and synthesizing (Bloom's taxonomy, 1956). This encourages task persistence, which is even more important than the knowledge of learning strategies (Gersten, 2001), what eventually increases the learners chance to achieve text understanding. Indeed, concreteness is the main vehicle of the IP and around which self-regulation (Nash-Ditzel, 2010) is evolving and abstract thinking is triggered. In fact, self- regulation seems crucial for LD's who need to compensate for their limited schema (Zhang, 2005) and other deficits typical of their learning disabilities. In addition, self-regulation caters to learners' feelings and hopes (Schwartzer, 2009) since it gradually builds up feelings of control and progress. Although the principles of the IP resemble well known theories and didactics, some lacunae still exist in the field of L2 among students with learning disabilities. First, no study, so far, in the field of reading comprehension in English as a second language (hereinafter ESL) explicitly articulated the importance of activating concrete thinking levels as a prerequisite to 


\section{International Journal of Advanced Multidisciplinary Scientific Research (IJAMSR) ISSN:2581-4281}

abstract thinking for LD students. A similar approach is adopted by Galperin (2010) but he focuses on the processes of thinking mainly in the disciplines of mathematics and basic reading. Second, although the extant literature acknowledges the role of SE in learning, only few studies have been directed towards the development of SE in this field (Raoofi et al., 2012). Third, only little attention has been given to the perceptions of many subgroups in the field of foreign language learning, such as ESL (Wesely, 2012). Previous studies have shown that university students having low or intermediate English proficiency levels (European A and B levels: Council of Europe, 2001) tends to process, expository texts in English (as FL/L2) at word or microstructural level, showing macrostructural processing difficulties (Kozminsky\&Graetz, 1986; Koda, 1990, 1996). These macrostructural problems seem to be associated with poor metacognitive comprehension monitoring when reading (Gómez \&Sanjosé, 2012; Gómez, Devís\&Sanjosé, 2013). Usual instructional approaches have attributed these problems to students' lack of language proficiency and have focused on providing students with more lexical and grammatical knowledge. However, some studies have shown that when the subjects' proficiency level increased to the European C1, some macrostructural problems do not disappear, in comparison to the subjects' L1 performance (Gómez \&Sanjosé, 2012; Gómez, Devís\&Sanjosé, 2013). Some authors pointed out these problems in the past and recommended an instructional shift from surface to macrostructural approaches in English (as FL/L2) teaching (Block, 1992; Stanley, 1984). In previous studies Gómez, Devís\&Sanjosé $(2012,2014)$ validated an instructional procedure which improved comprehension monitoring and L2/FL macrostructural processing when reading Science texts. This method concentrated on reading strategies rather than on vocabulary and grammar comprehension. This instruction proved to be very efficient but, beyond validation studies, it needed to be contrasted with another control procedure.

\section{Review of Literature}

lshwiah (2009) investigated the effects of a proposed blended learning strategy and analyzed students' attitudes toward the English language at Arabian Gulf University. The sample was divided into two groups: control group and experimental group. Findings indicated no significant difference between two groups regarding achievement or attitude towards English Language.

Similarly, Chang et al. (2014) conducted a study to examine the effects of blended e-learning on electrical machinery performance. Participants were two classes of the graders majoring in electrical engineering. The participants were randomly selected and assigned to the experimental group or the control group. The experiment lasted for 5 weeks. The results showed that there were no significant differences in achievement test scores between blended e-learning and traditional learning. His recognition of vocabulary as a crucial component of second language knowledge and skills has led to the investigation of different strategies and techniques of vocabulary instruction in classrooms and their effects on the learning and retention of vocabulary items. One of the well-known vocabulary instructional strategies involves presenting the novel L2 vocabulary items with their L1 translations. The effectiveness of using L1 words in learning. 


\section{International Journal of Advanced Multidisciplinary Scientific Research (IJAMSR) ISSN:2581-4281}

Kamel et al. (2009) propose an approach based on Web data sources, including forms that are a source of structured data. Their study uses various properties of these documents, with the combination of a layout analysis, a linguistic analysis and semantic annotation. They propose to construct a domain ontology in two stages: the first is to build a core ontology and the second is to enrich it. Silva et al. 13propose an alignment in several stages: in the first stage, they gather the terms of the first three levels of the domain ontology, and associate them to the concepts of the basic used ontology. Then other preliminary steps are also considered, such as extraction and cleaning of fragments. The alignment is then applied with selected measures, based on the OMN standard (Naïve Ontology Mapping) used by the FOAM tool6. Carvalho et al. 3look for implicit information in the domain ontology, and operate the way it can be extracted by improving various processes, notably the alignment. This approach uses data mining techniques to extract new terms and relations from ontologies, to allow their semantic improvement, by enriching ontologies with these elements. Carvalho et al. 4consider the enrichment of ontologies with relations and implicit terms contained in the definitions of ontologies, as well as the association of the ontology concepts to the categories of the basic ontologies. Some old ontology learning systems are described in12. Previous studies have shown that university students having low or intermediate English proficiency levels (European A and B levels: Council of Europe, 2001) tends to process, expository texts in English (as FL/L2) at word or microstructural level, showing macrostructural processing difficulties (Kozminsky\&Graetz, 1986; Koda, 1990, 67Ángela Gómez et al. / Procedia - Social and Behavioral Sciences
173 (2015 ) 66 - 70 1996). These macrostructural problems seem to be associated with poor metacognitive comprehension monitoring when reading (Gómez \&Sanjosé, 2012; Gómez, Devís\&Sanjosé, 2013).

Nation (2001) points out, "vocabulary learning is not a goal in itself; it is done to help learners listen, speak, read, or write more effectively"(p. 362). As a result, learning a language is dependent on learning its vocabulary. Teachers are frequently encountered with questions posed by their students regarding the meanings of new vocabularies. It is often the case that a great portion of class time is spent on teaching vocabularies. Therefore, if appropriate techniques are not applied in the class, the final outcome may frustrate teachers. In order to teach students how to learn new vocabulary, teachers need to draw on a variety of teaching strategies in accordance with different vocabulary learning techniques. To this end, many studies have investigated the effect of different methods on vocabulary teaching and learning (e.g., Nation, 1990, 2001; Laufer et al., 2005; Schmitt, 2000; to name a few).

\section{Research method}

The participants of the present research are all EFL learners in the Universities of Ilam in two grades of M.A and B. A that are 393 cases. A Michigan proficiency test was done in determining the level of proficiency and then 120 cases were selected based on their scores from Michigan test, as a case study in whom 60 are males and 60 are females and the age range of them is 20-35 years. The research method in the present study is descriptiveanalytic, data are collected by following instruments:

Research made questionnaire: it is including demographic data

Vocabulary test: it is including standardized test by 


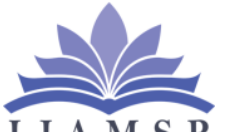

\section{International Journal of Advanced Multidisciplinary Scientific Research (IJAMSR) ISSN:2581-4281}

Victoria University of Willington that is including 100 multiple Items. Because of length of the test we use 35 items on them.

Standard texts: it is included standard texts of reading by Oxford University.

In the present research, research population is divided into two groups, control and experimental. The division of the population is random and there are 60 males and 60 females in each group. At first the vocabulary test is done for leveling learners, and then the experiment group receives texts and education of text reading for 8 sessions, while control groups do not receive it.

The participants would complete a questionnaire and also the take vocabulary test and SPSS software will be used to analyze the data. T-test will be used to check differences between male and female participants and finally post hours of Tokay will be used to determine points of differences.

\section{Research Findings}

Question (1): Is there any relationship between textualization and learning vocabulary among Iranian EFL learners?

The following findings were obtained to first Question.

Table1, Findings for Difference between Control and Experimental Groups for learning vocabulary.

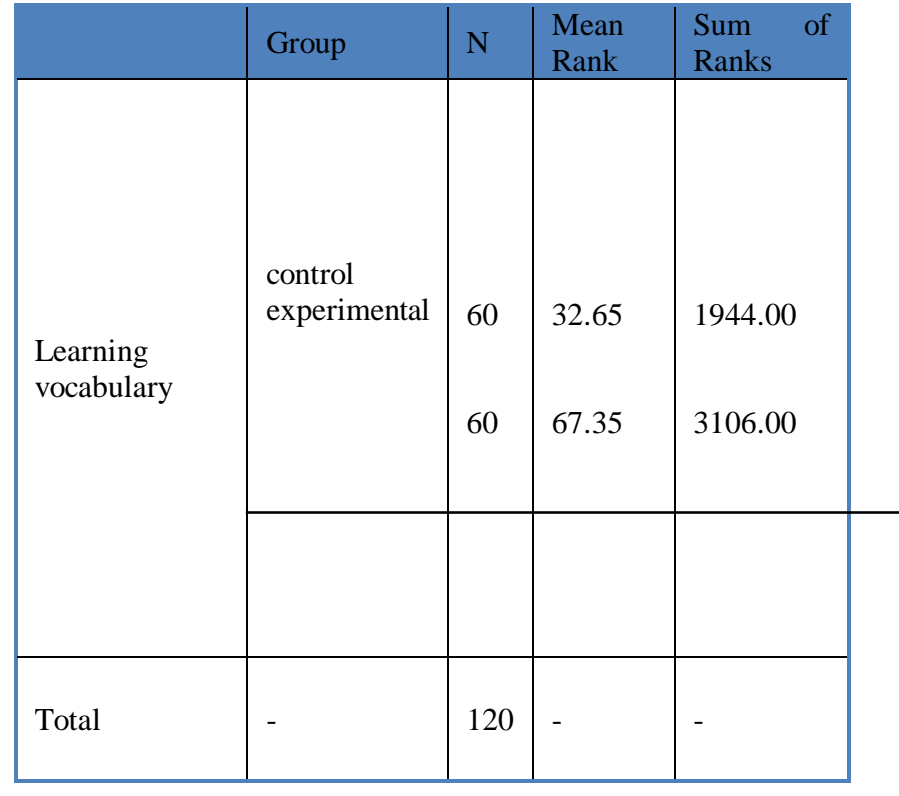

The following table presented obtained results from the Mann-Whitney test regarding the comparison between the average scores of learning vocabulary for control and experimental groups.

\section{Table 2, Table of Mann-Whitney $U$}

\begin{tabular}{|l|l|}
\multicolumn{1}{l|}{} & Learning vocabulary \\
\hline Mann-Whitney U & 670.000 \\
\hline Wilcoxon W & 1945.000 \\
\hline Z & -4.407 \\
\hline Asymp. Sig. (2-tailed) & .000 \\
\hline
\end{tabular}

According to Table 4.7, average scores of learning vocabulary for control and experimental groups as well as the comparison of $(w=669.000 a n d z=-4.405)$ presented in the table at the significance level of $(p=$ 0.000), it can be said that there is a significant difference between control and experimental groups for learning vocabulary at the 5 percent error level and the 95 percent confidence level. Hence, it can be said that there is significance relationship between textualization and learning vocabulary among Iranian EFL learners. 
https://doi.org/10.31426/ijamsr.2018.1.6.616

\section{International Journal of Advanced Multidisciplinary Scientific Research (IJAMSR) ISSN:2581-4281}

Question (2): Is there any relationship between text authority and learning vocabulary among Iranian EFL learners?

Following table indicated differences in learning vocabulary among experimental group that used original texts and control group which not used these texts.

Table 3, The Results for the Difference between the Control and Experimental Groups for learning vocabulary

\begin{tabular}{|l|l|l|l|l|}
\hline & group & $\mathrm{N}$ & $\begin{array}{l}\text { Mean } \\
\text { Rank }\end{array}$ & $\begin{array}{l}\text { Sum of } \\
\text { Ranks }\end{array}$ \\
\hline $\begin{array}{l}\text { Learning } \\
\text { vocabulary }\end{array}$ & Control & 60 & 35.07 & 1951.00 \\
\hline & Experimental & 60 & 64.93 & 3099.00 \\
\hline & Total & 120 & & \\
\hline
\end{tabular}

Table 4, The findings of Mann- Whitney table is presented as follows:

Test Statistics

\begin{tabular}{|l|l|}
\multicolumn{1}{l|}{} & Learning vocabulary \\
\hline Mann-Whitney U & 686.000 \\
\hline Wilcoxon W & 194.13 \\
\hline Z & -4.035 \\
\hline Asymp. Sig. (2-tailed) & .000 \\
\hline
\end{tabular}

According to obtained data from the Mann-Whitney test as well as the comparison of $(w=676.000 \mathrm{andz}=$ -4.065) presented in the table at the significance level of $(p=0.000)$, it can be said that there is a significant difference among the control and experimental groups for learning vocabulary at the 5 percent error level and the 95 percent confidence level.

$\mathrm{n}$ words of texts ./51).

Question (3): What are the factors of textualization for learning vocabulary among Iranian EFL learners?

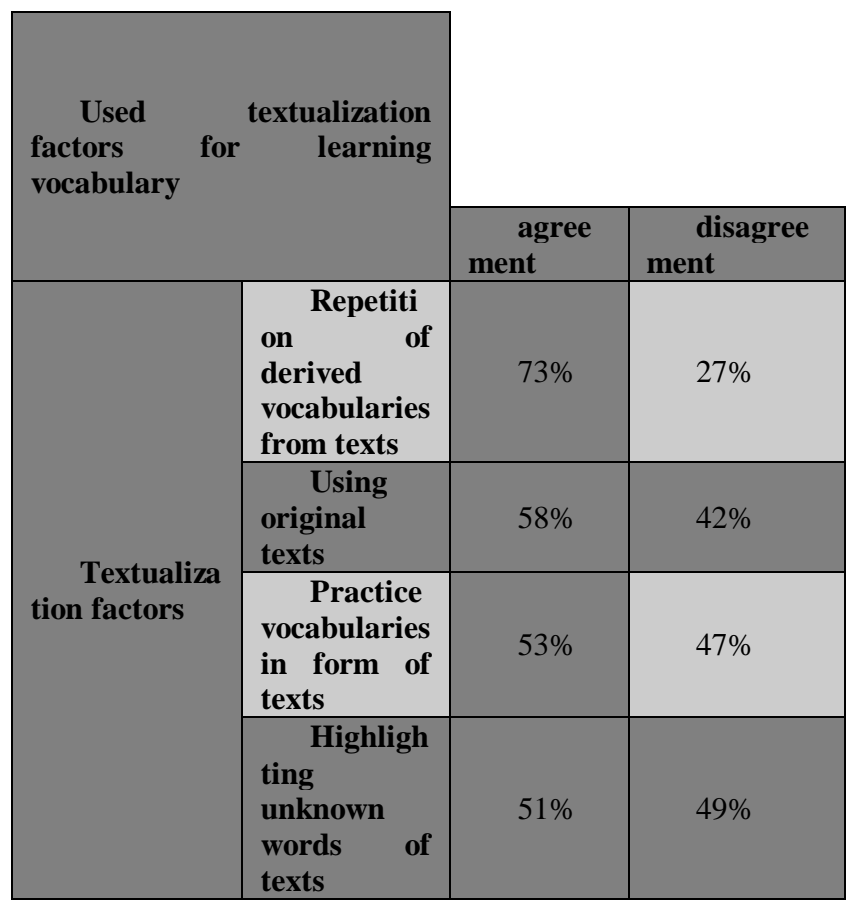

According to the above table, four components of textualization use of EFL learners in Ilam that are as follows: Repetition of derived vocabularies from texts (. /73), using original texts (. /58), Practice vocabularies in the form of texts (/.53), Highlighting unknown words of texts. /51). 


\section{International Journal of Advanced Multidisciplinary Scientific Research (IJAMSR) ISSN:2581-4281}

\section{Conclusion \&Discussion}

Both first language (L1) learners and second language (L2) learners may incidentally gain knowledge of meaning through reading. While researchers tend to agree that incidental learning is responsible for the vast majority of L1 vocabulary learning, there is some suggestion that explicit learning of vocabulary may be responsible for most L2 vocabulary learning. However, researchers agree that incidental vocabulary learning should be encouraged and incorporated into L2 learning. The present research is aimed at investigating textualization on learning vocabulary. To this aim, 120 EFL learners were selected randomly and were tested in two groups of experimental and control groups. The findings of the present research indicated that textualization has a significant effect on learning vocabulary.

The present research tested an experimental aspect of the language learning and so it can be said it is an operational study and students can use it during learning their language. The relationship between vocabulary and reading has been a well-established notion among the teachers of English as a foreign language and language teaching theoreticians. There is no doubt that reading in English and the vocabulary knowledge of learners of English as a foreign language is directly related to each other. Anderson and Free body (1981) state that it is the general vocabulary knowledge of the reader that best predicts how well that reader understands the text. Nagy (1988) states that vocabulary is fundamental to comprehension of various texts and that vocabulary teaching should be an integral part of language education. While there is a consensus on the importance of vocabulary in reading performance, ideas on how vocabulary should be taught and how much of it should be given to the learners may vary. While some put forward that vocabulary should be taught explicitly in classrooms, some others came up with different ways to teach vocabulary.

\section{Suggestions for further researches}

- 1 -the present research investigated the effect of textualization on learning vocabulary, it is suggested to investigate the effect of this variable on other language skills of language.

- 2 - Since the present research was done in Ilam area, so it is suggested to do this study in other areas to evaluate of validity and reliability of the present research,

- 3- The present research is involved with time limitations, so it is suggested in this study in other times

\section{Limitations of the study}

The present research similar to all other studies is followed with some limitations:

- The present research was done in Ilam province, so it can be said the present research is following with time limitation.

- Since the present research was done in a specific time, so the present research is involved with time limitation.

- Since the present research used limited sample, so the present research is involved with limitation in the research sample. 


\section{International Journal of Advanced Multidisciplinary Scientific Research (IJAMSR) ISSN:2581-4281}

\section{References}

1) Alshwiah, A. A. S. (2009). The effects of a blended learning strategy in teaching vocabulary on premedical students' achievement, satisfaction and attitude toward English language (Published master thesis). Arabian Gulf University, Bahrain.

2) Bandora, D. (2006). Blended e-learning: Integrating knowledge, performance support, and online learning.

3) Cheng, C., Shu, K., Liang, C., Tseng, J., \& Hsu, Y. (2014). Is blended e-learning as measured by an achievement test and self- assessment better than traditional classroom learning for vocational high school students? IRRODL, 15 (2)

4) -Chen, H. C. (1990). Lexical processing in a nonnative language: Effects of language proficiency and learning strategy. Memory and Cognition, 18, 279288.

5) Chen, H. C., \& Leung, Y. S.(1989). Patterns of lexical processing in a nonnative language. Journal of Experimental Psychology: Learning, Memory, and Cognition, 15(2), 316-325.

6) De Groot, A. (1993). Word-type effects in bilinguals processing tasks: Support for a mixedrepresentational system. In $R$. Schreuder\& $B$. Weltens (Eds.), The bilingual lexicon(pp. 27-51). Amsterdam: Benjamins.

7) -Jahromi, A. (2014) Collecting data using a semistructured interview: A discussion paper. Journal of Advanced Nursing, 19(2), pp.328-335

8) Gómez \&Sanjosé, (2012). Effects of Online Academic Lectures on ESL Listening Comprehension, Incidental Vocabulary Acquisition, and Strategy Use, Computer Assisted Language Learning17 (5), 525-564.

9) -Khazaei, S., Dastjerdi, H.V. (2011). An Investigation into the Impact of Traditional vs. Blended Teaching on EFL Learners' Vocabulary Acquisition: M-learning in Focus. International Journal of Humanities and Social Science, 1(15), 202-207

10) -Lightbown, P.M. \&Spada, M. (2013).How languages are learned (fourth edition). Oxford: Oxford University Press.

11) -Marsh, D. (2012). Blended learning: Creating learning opportunities for language learners

12) . New York: Cambridge University Press.

13) -Nation, M. (2001), Blended learning and its potential in expanding vocabulary knowledge: A case study. Teaching English with Technology, 10(1),pp. 3-30.

14) -Kamel, T., Koyun, A., Yuksel, A. \&Cankaya, I. (2009). Evaluation of Blended Learning Approach in Computer Engineering Education, Procedia-Social and Behavioral Sciences 141,807-812
15) -Zhang, H., Song, W., \&Burston, J. (2011). Reexamining the effectiveness of vocabulary learning via mobile phones. The Turkish Online Journal of Educational Technology, 10 (3), 203-214

16) -Kroll, J. F. (1993). Accessing conceptual representations forwards in a second language. In $R$. Schreuder\& B. Weltens (Eds.), The bilingual lexicon(pp. 58-81). Amsterdam: Benjamins.

17) -Kroll, J. F., \& Curley. J. (1988). Lexical memory in novice bilinguals: The role of concepts in retrieving second language words. In M. M.

18) -KamelM. ,Aussenac-Gilles N., Buscaldi D., Comparot C, A semi-automatic approach for building ontologies from a collection of structured web documents. In: 7th International Conference on Knowledge Capture (K-CAP'13). Banff, Canada, June 2013.

19) -Reese, L. \&Gallimore, R. (2000). Immigrant Latinos' cultural model of literacy development: An evolving perspective on home-school discontinuities. American Journal of Education, 108(2), 103-134.

20) Sanders, M. G. and Epstein, J. L. (1998). Schoolfamily-community partnerships and educational change: International perspectives. In A. Hargreaves, A. Lieberman, M. Fullan, and D. Hopkins (eds.) International Handbook of Educational Change. Hingham MA: Kluwer.

21) Sénéchal, M., \&LeFevre, J. (2002). Parental Involvement in the Development of Children's Reading Skill: A Five Year Longitudinal Study. Child Development, 73(2), 445-460. U.S. Department of Education. National Center for Education Statistics. 1993 National Household EducationSurvey (NHES:93) Questionnaires: Screener, School Readiness, and School Safety and Discipline, Working Paper No. 96-21. Project Officer, Kathryn Chandler. Washington, D.C.: 1996.

22) Shamsfard M., and Barforoush A. A., The State of the Art in Ontology Learning: A Framework for Comparison. Intelligent Systems Laboratory. The Knowledge Engineering Review; 2003. Vol. 18, Issue (4). 